\title{
Total Abuse of the Earth: Human Overpopulation and Climate Change
}

\author{
J. T. Trevors
}

Published online: 7 October 2009

(C) Springer Science + Business Media B.V. 2009

Abuse comes in many forms to humans - verbal, physical, emotional, economic/poverty, hunger, greed, and religious discrimination-sometimes subtle and sometimes with violence. These are only a few examples. What about the abuse that too many humans inflict daily on our planetary biosphere? We are addicted to oil, consumption of all resources, waste, and pollution, to name a few examples. The total planetary abuse is the extraction of hydrocarbons from the Earth and depositing the gasses and particulates in the atmosphere, oceans, soils, and bodies of animals. This form of abuse is the total pollution of our biosphere.

To complicate the situation, add about 6.6 billion humans to the planet with an increase of 75 million humans annually. This is also abuse of our common shared biosphere. Combine global pollution/climate change with uncontrolled human population growth, and you have the perfect recipe for total planetary abuse. Add a few wars, unstable governments, dictatorships, corporate and individual greed, crime, lack of basic human rights and needs, violence and countries armed with every means of destruction

J. T. Trevors $(\bowtie)$

Department of Environmental Biology,

University of Guelph,

Guelph, Ontario, Canada NIG 2W1

e-mail: jtrevors@uoguelph.ca possible, and you have a more complex recipe for total global abuse.

Since this has all been said before, and many people did not heed the message or act upon the current situation, it is often necessary to remind humans again and again that total planetary abuse was never sustainable economically, socially, environmentally, or thermodynamically. For every barrel of oil extracted and consumed as an energy source, there is a corresponding amount of mass in the form of pollution (and heat as a byproduct) produced. Antoine Lavosier discovered and stated the first law of conservation of mass over two centuries ago. The mass of a closed system will remain constant regardless of the processes or event in the closed system. The mass of the reactants equals the mass of the products. Where does all that pollution from burning fossil fuels go? Into the atmosphere, ocean, soils, and living creatures of the planet while being consumed in heat engines or other devices and industrial processes. The perfect pollution machines are not very efficient. Automobiles are in the range of $20-25 \%$ efficient. The remainder is heat and exhaust pollution.

Humans are not denying that we need energy for electrical generation, transportation, food production, and manufacturing to name a few examples. We all consume and we all pollute; some more than others. Cold climates are difficult to live in without energy sources for heating. However, adding 75 million more people to a bulging, hungry planet on a yearly basis is 
the priority problem that humanity must solve if we want to control planetary abuse. The answer is universal human birth control and energy efficiency and conservation, while non-fossil fuel energy sources are made available. Human birth control will give us some much needed time to determine and implement the best solutions to energy usage.

Total abuse of the planet Earth is not intelligent and sustainable. The party is over. The harsh reality is one that no human will enjoy. No amount of wishful thinking or denial by humans will decrease the magnitude of the problems facing humanity. Ridiculous statements such as - the problem is contained, the loses are real, the next crisis, the act of buying makes you rich-are meaningless when there are too many humans on the planet consuming too many resources and generating too much global pollution. This has been stated before, but not everyone listened, so it is being stated again.

Save yourself and the planet. The weapons of mass environmental destruction are human population growth and total global pollution. Thou shall not pollute. Honor thy planet. Thou shall not destroy the planet and future generations. Thou shall not covet another country's oil. Thou shall not kill for oil. Instead, we see and hear-I want your oil. I want your money. I want your water. I want it all. Let's consume and burn oil. I am special. I am better. I am entitled. Consume, consume, consume, and then consume some more while placing yourself in debt and maybe bankruptcy. This is supposedly good for the global economy.

Humans cannot bribe nor buy nature. Pollution is everywhere. To think there are technological fixes to all our global problems is wishful thinking. The real environmental challenge is to change the minds of humans and to synchronize the global economy with environmental sustainability. The economic crisis is really a crisis in stupidity and greed by some humans. The economic crisis pales in comparison to the real environmental crisis.

As an endnote, humans do not care what socalled celebrity $\mathrm{X}$ was wearing last night. Give it a rest and do something useful for humanity. The mass media could assist in educating humans instead of unleashing the forces of trivialization upon us. One of the last frontiers is educating the human mind in a meaningful way. 